\title{
Velcro Straps as A Convenient Alternative to Fasten Plaster of Paris Splints
}

\author{
Venkatesh Rajaram Sawant ${ }^{1}$ ～Chandrakant R Gharwade ${ }^{2}$ Sagar Gundewar ${ }^{2}$
}

${ }^{1}$ Department of Plastic and Reconstructive Surgery, Goa Medical College, Panaji, Goa, India

${ }^{2}$ Department of Plastic and Reconstructive Surgery, Grant Medical College and JJ Group of Hospitals, Mumbai, India

Indian J Plast Surg 2021;54:377-378.

Plaster of Paris (POP) slabs are frequently used in plastic surgery for splintage to immobilize part of a limb. Traditionally, we have always used elastic bandage ${ }^{1}$ for fastening the plaster of Paris slab onto the limb after setting the POP in the desired position. Although very effective and easy, these bandages often get loose, resulting in loss of desired position or permit excessive motion ${ }^{2}$ within the splint. We have tried using velcro straps as an alternative to bandages, and found it to be better in some aspects.

It is very easy to add velcro straps to a POP splint. POP of appropriate length, width, and layers is selected. This is then put against the limb, and markings made for strap placement ( - Fig. 1). Straps of velcro are cut at appropriate length, according to the circumference of the limb and the width of the POP. Initially, these straps can be kept longer, and they can be trimmed afterward accordingly. The ends of male and female straps are stuck to each other for approximately 1 to $2 \mathrm{~cm}$ The POP is moistened in water and laid onto a flat surface. The straps are now inserted between the layers of the POP, according to the previously done markings ( $\mathbf{- F i g . ~ 2 ) . ~}$ The slab is then positioned over the limb and shaped to give the desired position, while the POP is setting the edges of the plaster and molded inward toward the limb. This curls the velcro strap inward and provides more stability. The POP is then allowed to set, and after drying, the straps are fastened over the limb ( $\boldsymbol{- \text { Fig. }} \mathbf{3}$ ). Any extra length of strap is trimmed now.

With use of these velcro straps, it becomes convenient to reapply the splint in proper position when it becomes loose. This can also be done by the patient themselves. It also makes frequent change of dressing more comfortable for patient and surgeon. Premade splints of thermoplastic material are available with velcro straps, which provide the same advantages, but they are not custom-made for a patient's anatomy or particular condition. ${ }^{3}$ Custom-made thermoplastic splints are made with velcro straps, but it requires a therapist to measure and ensure a good fitting. ${ }^{3}$ POP splints with velcro straps can provide an effective alternative in such conditions.

published online

September 27, 2021
DOI https://doi.org/

$10.1055 / \mathrm{s}-0041-1735418$ ISSN 0970-0358
Address for correspondence Venkatesh Rajaram Sawant, Department of Plastic and Reconstructive Surgery, Goa Medical College, Panaji, Goa, India (e-mail: reconvenky@gmail.com).

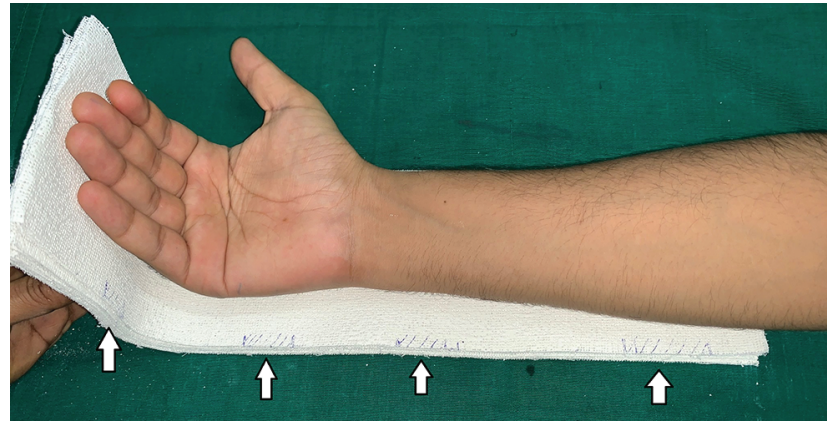

Fig. 1 Markings for strap placements

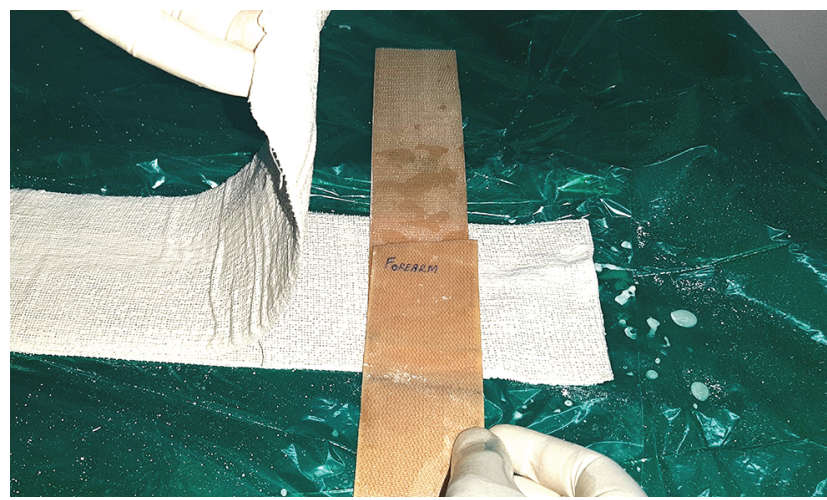

Fig. 2 Placing the straps between the layers of wet plaster of Paris (POP).

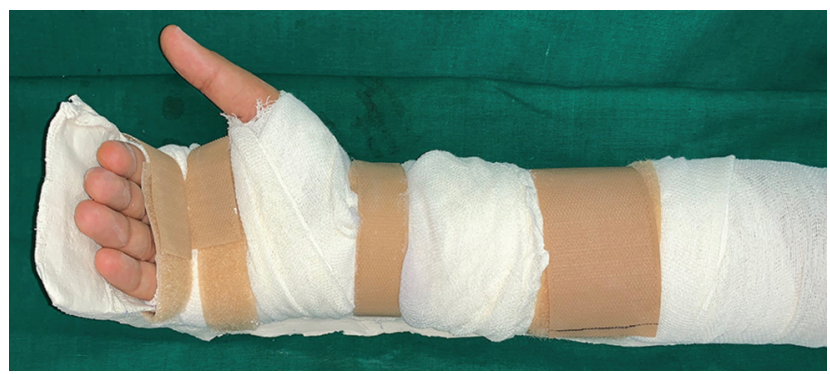

Fig. 3 Final application of splint

(c) 2021. Association of Plastic Surgeons of India.

This is an open access article published by Thieme under the terms of the Creative Commons Attribution-NonDerivative-NonCommercial-License, permitting copying and reproduction so long as the original work is given appropriate credit. Contents may not be used for commercial purposes, or adapted, remixed, transformed or built upon. (https://creativecommons.org/licenses/by-nc-nd/4.0/).

Thieme Medical and Scientific Publishers Pvt. Ltd. A-12, 2nd Floor, Sector 2, Noida-201301 UP, India 
The main drawback of this technique is the adhesiveness of the Velcro straps which decreases with time and sometimes these straps slip out from between the layers of plaster, when a new plaster has to be made.

\section{Conflict of Interest}

None declared.

\section{References}

1 Colditz JC. Plaster of Paris: the forgotten hand splinting material. J Hand Ther 2002;15(2):144-157

2 Boyd AS, Benjamin HJ, Asplund C. Principles of casting and splinting. Am Fam Physician 2009;79(1):16-22

3 Chudnofsky, CR, Chudnofsky, AS, Splinting techniques. In: Roberts and Hedges: Clinical Procedures in Emergency Medicine and Acute Care 7th ed. St. Loius, MO: Elsevier; 2019 1027-1055 